\title{
Patogenicidade de Penicillium sclerotigenum a Diferentes Frutas e Hortaliças em Pós-Colheita
}

\author{
Idjane S. Oliveira ${ }^{*}$, Romero M. Moura², Edna Dora M. N. Luz ${ }^{3}$ \\ \& Leonor C. Maia $^{4}$
}

\begin{abstract}
${ }^{1}$ Departamento de Ciências Biológicas, Universidade Estadual de Santa Cruz, CEP 45600-000, Ilhéus, BA, e-mail.: idjaneoliveira@yahoo.com; ${ }^{2}$ Departamento de Agronomia, Área de Solos/Microbiologia, Universidade Federal Rural de Pernambuco, CEP 52171-900, Recife, PE; ${ }^{3}$ CEPLAC/CEPEC/Seção de Fitopatologia, Cx. Postal 07, CEP 45650000, Itabuna, BA; ${ }^{4}$ Departamento de Micologia, Universidade Federal de Pernambuco, CEP 50670-420, Recife, PE
\end{abstract}

(Aceito para publicação em 24/08/2006)

Autor para correspondência: Idjane Santana de Oliveira

OLIVEIRA, I.S., MOURA, R.M., LUZ, E.D.M.N. \& MAIA, L.C. Patogenicidade de Penicillium sclerotigenum a diferentes frutas e hortaliças em pós-colheita. Fitopatologia Brasileira. 31:408-410. 2006.

\section{RESUMO}

Foi estudada a patogenicidade do Penicillium sclerotigenum, agente etiológico da podridão-verde do inhame, em quinze frutas e hortaliças diferentes. Após a realização de ferimentos em órgãos vegetais sadios, inoculou-se um isolado, reconhecidamente virulento do fungo sobre estas áreas. As avaliações foram feitas mediante uso de uma escala crescente de notas, indicando grau de susceptibilidade de 1 a 3 . Os resultados demonstraram que maçã, pêra e banana, além das testemunhas positivas inhame da Costa (Dioscorea cayennensis), inhame nambu (D. alata) e taro, foram suscetíveis. As demais espécies estudadas foram moderadamente suscetíveis: batata inglesa, beterraba, berinjela e taro, ou resistentes: chuchu, cenoura, mamão, pepino, abobrinha, batata doce e aipim. Estes resultados ressaltaram a necessidade de ser evitada a contaminação de embalagens e ambientes compartilhados para a armazenagem do inhame e outros produtos suscetíveis à infecção de $P$. slerotigenum, especialmente banana, maçã e pêra, principalmente nos trópicos, onde o inhame é muito cultivado e a podridão-verde altamente disseminada. Os resultados obtidos indicaram também que, além das perdas de inhame durante o armazenamento, também perdas de banana, maçã e pêra possam ocorrer devido ao ataque deste fungo. Penicillium sclerotigenum pode ter uma gama de hospedeira bem mais ampla, resultando em maiores riscos de produção de patulina em produtos armazenados. Esta micotoxina tem atividades mutagênica, carcinogênica e teratogênica, demonstrada experimentalmente em animais, sendo a pêra e a maçã bons substratos para sua produção.

Palavras-chave adicionais: podridão-verde, gama de hospedeiro, suscetibilidade.

\begin{abstract}
Post-harvest pathogenicity of Penicillium sclerotigenum to fruits and vegetables.

The aim of this investigation was to study the pathogenicity of the fungus Penicillium sclerotigenum, the causal agent of the green-rot of yams (Dioscorea spp.) on different fruits and vegetables. A highly virulent isolate of the fungus was wound-inoculated on selected fruits and vegetables. A disease index ranging from 1 to 3 was adopted in order to rank disease susceptible. The results pointed out apple, pear and banana as highly susceptible; potato, beet, eggplant and taro as relatively susceptible and charlotte, carrot, papaya, zuchinni, sweet-potato and cassava as resistant to infection. These results indicated the need of special care when packaging and storage areas are utilized for both yams and other products susceptible to infection by P. sclerotigenum, particularly bananas, apples and pears. So far, P. sclerotigenum has been reported only on yams and these new finding also indicate that, besides yams losses, storage losses of apple, pear and banana may also occur. Penicillium sclerotigenum ability to infect these other products may represent an additional source of patulin in under storage conditions. This mycotoxin has well demonstrated mutagenic, carcinogenic and teratogenic effects on animal and apple and pear are known to be good substrates for patulin production.
\end{abstract}

Additional keywords: green-rot, host range, susceptibility.

Penicillium sclerotigenum Yamamoto é agente etiológico da doença podridão-verde do inhame (Dioscorea spp.), descrita no Brasil por Moura et al. (1976) incidindo em túberas sementes e comerciais de D. cayennensis Lam.,

* Parte da Tese de Doutorado da primeira autora. Universidade Federal de Pernambuco. Recife. 2005. o inhame da Costa. Trata-se de uma doença que ocorre durante o armazenamento de túberas comerciais e sementes, causando perdas no plantio, por induzir estiolamento de pré e pós-emergência (Santos, 2002) no armazenamento. A denominação podridão-verde deve-se ao desenvolvimento micelial que ocorre superficialmente na área infectada, com a presença de conidióforo e conídios de coloração verde. Moura et al. (1976), não conseguiram reproduzir a doença em 
outras plantas, possivelmente devido o período de avaliação ter sido de apenas sete dias, concluindo que, provavelmente, P. sclerotigenum possuía patogenicidade específica, causando podridão úmida, profunda, de coloração marrom, apenas em túberas de inhame da Costa e São Tomé (D. alata L.), neste último, com menor virulência. Segundo Adeniji (1970) na Nigéria, Oeste da África, além de P. sclerotigenum, $P$. oxalicum Currie \& Thom causa sintomas semelhantes em Dioscorea spp., porém, no Brasil, tal ocorrência ainda não foi constatada.

O objetivo da presente investigação foi estudar a suscetibilidade a este fungo em pós-colheita de frutos e hortaliças selecionados, a saber: maçã, pêra, banana, mamão, aipim, beterraba, cenoura, batata inglesa, batata doce, inhame da Costa, inhame nambu, taro, abobrinha, berinjela, chuchu e pepino. A justificativa de tal investigação prendeu-se ao fato de $P$. sclerotigenum possuir alto poder de disseminação, causar elevadas perdas, além de produzir micotoxinas, especialmente a patulina (Frisvad \& Samson, 2004).

As amostras de frutos e hortaliças utilizados neste estudo foram adquiridas no comércio de frutos e hortaliças de Recife. Para as inoculações, utilizou-se o isolado (BA-30) obtido do inhame da costa, proveniente do Estado da Bahia. Este isolado apresentou intensa produção de esclerócios e pigmento marrom em meio BDA, características típicas da espécie $P$. sclerotigenum. As superfícies dos órgãos vegetais a serem inoculados foram desinfestadas com água e sabão, e em seguida, tratadas com álcool etílico a $70 \%$, por imersão durante $15 \mathrm{~s}$. Após a secagem total das superfícies, procederam-seasinoculações. Utilizaram-secincorepetições, cada uma representada por um órgão-fruto ou tubérculo, para cada espécie estudada, tomando-se o inhame da Costa e inhame nambu (D. alata) como testemunhas positivas para susceptibilidade. Sabe-se que $P$. sclerotigenum penetra sempre no inhame por ferimentos (Moura et al., 1976). Portanto, antes da inoculação foi feita uma pequena incisão, com cerca de $1 \mathrm{~cm}$ de comprimento, em três posições nos frutos, tubérculos ou raízes a saber: parte apical, intermediária e basal. Em seguida, depositou-se, sobre os pontos feridos um disco de cultura de $P$. sclerotigenum, produzido em $\mathrm{BDA}$, com $5 \mathrm{~cm}$ de diâmetro, proveniente de cultura pura do isolado, após sete dias de cultivo. Seguiu-se a manutenção das amostras em câmara úmida, distribuídas na bancada de modo inteiramente casualisado, em ambiente de luz natural e temperatura ambiente, com média de aproximadamente $28{ }^{\circ} \mathrm{C}$. Para avaliação da suscetibilidade do hospedeiro, usou-se uma escala crescente de notas, de 1 a 3, aplicada do seguinte modo: 1 = ausência de sintomas (resistente) , 2 = infecção discreta - área colonizada menor do que o dobro da área inoculada, observada visualmente (moderadamente suscetível); 3 = infecção severa - área colonizada maior do que o dobro da área inoculada (suscetível). As avaliações foram feitas 10 dias após a inoculação para os frutos e 20 dias para hortaliças, raízes e tubérculos. Após a aplicação das respectivas notas, procedeu-se o reisolamento do fungo para todas as espécies vegetais estudadas, usando-se meio de cultura BDA e o método de isolamento indireto de fungos fitopatogênicos, descrito em Menezes \& Assis (2004). Após um mês o experimento foi repetido nas mesmas condições, utilizando-se os frutos e hortaliças obtidos no mesmo supermercado, na mesma quantidade, usando-se o mesmo isolado fúngico e as mesmas condições de manutenção das amostras.

Os resultados de suscetibilidade encontram-se na Tabela 1, e a Figura 1 mostra exemplos das reações obtidas para as inoculações. A susceptibilidade, especialmente da maçã e pêra, destacaram-se em importância pelo fato desses frutos serem reconhecidamente bons substratos para produção de patulina, micotoxina estudada no patossistema envolvendo o fungo P. expansum Link (Sommer et al., 1974). Tal substância é produzida também por $P$. sclerotigenum, tendo sido relatada em cultura tipo da espécie, pertencente à coleção internacional (CBS), sem, contudo, ser feita a indicação do substrato de onde o isolado foi obtido (Frisvad \& Samson, 2004). Além desta micotoxina, sabe-se que $P$. sclerotigenum também produz outros metabólitos importantes, tais como gregatinas, esclerotigenina e roquefortina C e D (Frisvad \& Samson, 2004). Pesquisas adicionais são necessárias para análises qualitativas e quantitativas de metabólitos de P. sclerotigenum produzidos nestes novos hospedeiros e também no inhame. Beterraba, berinjela, taro e batata inglesa apresentaram suscetibilidade moderada à infecção por $P$. sclerotigenum, enquanto que chuchu, mamão, abobrinha, pepino, batata doce, aipim e cenoura foram resistentes. Moura et al. (1976), obtiveram resultados diferentes em relação à batata inglesa, possivelmente devido ao tempo de incubação das amostras inoculadas para a avaliação dos

TABELA 1 - Patogenicidade de Penicillium sclerotigenum a diferentes frutos e hortaliças após 10 ou 20 dias de inoculação

\begin{tabular}{lccc}
\hline \hline Fruto / Hortaliça & D. A. I. * & S. H ** & Reação \\
\hline Inhame da costa & 20 & 3 & Suscetível \\
Inhame nambu & 20 & 3 & Suscetível \\
Taro & 20 & 2 & MS*** \\
Batata doce & 20 & 1 & Resistente \\
Batata inglesa & 20 & 2 & MS \\
Aipim & 20 & 1 & Resistente \\
Cenoura & 20 & 1 & Resistente \\
Maçã & 10 & 3 & Suscetível \\
Pêra & 10 & 3 & Suscetível \\
Banana & 10 & 3 & Suscetível \\
Mamão & 10 & 1 & Resistente \\
Abobrinha & 10 & 1 & Resistente \\
Berinjela & 10 & 2 & MS \\
Chuchu & 10 & 1 & Resistente \\
Beterraba & 20 & 2 & MS \\
Pepino & 10 & 1 & Resistente \\
\hline * D. A. I. = dias após a inoculação, & ** S. H. = \\
suscetibilidade do hospedeiro & {$[1-$} & resistente, 2- \\
moderadamente resistente (MS***) e 3-suscetível].
\end{tabular}




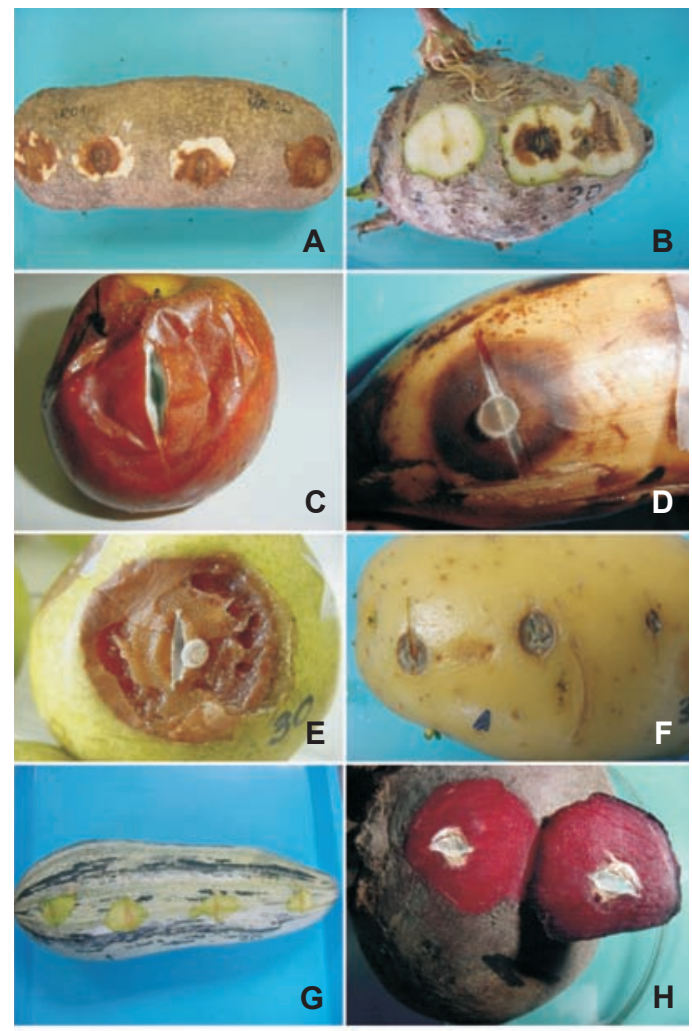

FIG. 1 - Reações induzidas experimentalmente pela inoculação em diferentes hospedeiros de P. sclerotigenum, após 10 dias (frutas e hortaliças) e 20 dias (raízes e tubérculos). A. Inhame da Costa (testemunha positiva para suscetibilidade); B.Taro (moderadamente suscetível); C. Maçã (suscetível); D. Banana (suscetível); E. Pêra (suscetível); F. Batata inglesa (moderadamente suscetível); G. Abobrinha (resistente); H. Beterraba (moderadamente suscetível).

resultados que foi de apenas sete dias, enquanto que nesta investigação foram 20 dias. Além disso, Frisvad \& Samson (2004) utilizaram, entre outras características, a capacidade de produzir podridão em maçã como diferenciadora entre as espécies Penicillium sclerotigenum e $P$. expansum, uma vez que, segundo os autores, apenas a segunda espécie induziria podridão em maçã. Os resultados deste trabalho mostram que $P$. sclerotigenum também é capaz de induzir podridão em maçã, independente da espécie de inhame de onde o isolado foi obtido. Inoculações em pêra, banana e maçã foram posteriormente repetidas com dois novos isolados de $P$. sclerotigenum oriundos de $D$. cayennensis e $D$. alata, sendo a podridão induzida nos dois casos, nesses hospedeiros.

A presente pesquisa indicou a necessidade de cuidados para a exclusão de $P$. sclerotigenum visando proteger ambientes ou embalagens que armazenam pêra, banana, maçã e inhames, especialmente quando houver uso comum de unidades de armazenagem ou embalagens, pois a podridão-verde é muito comum em inhame armazenado, principalmente nos trópicos.

\section{AGRADECIMENTOS}

Os autores agradecem ao CNPq pelo apoio financeiro, a Profa. Maria José dos Santos Fernandes da Micoteca URM -UFPE/Recife pela confirmação da identificação da espécie de Penicillium sclerotigenum.

\section{REFERÊNCIAS BIBLIOGRÁFICAS}

ADENIJI, M.O. Fungi associated with storage decay of yams in Nigeria. Phytopathology 60:590-592. 1970.

FRISVAD, J.C. \& SAMSON, R.A. Polyphasic taxonomyc of Penicillium subgenus Penicillium. A guide to identification of food and air-borne terverticillate Penicillia and their mycotoxins. In: Samson, R.A. \& Frisvad, J.C. (Eds.) Penicillium subgenus Penicillium: new taxonomic schemes, mycotoxins and their extrolites. Studies in Mycology 49:1-174. 2004.

MENEZES, M. \& ASSIS, S.M.P. Guia prático para fungos fitopatogênicos. $2^{\circ}$ Edição, Recife, Imprensa Universitária, UFRPE, $2^{\mathrm{a}}$ ed. 2004.

MOURA, R.M., RIBEIRO, G.P. COELHO, R.S.B. \& SILVA JÚNIOR, J.N. Penicillium sclerotigenum Yamamoto, principal fungo causador de podridão em túberas de inhame (Dioscorea cayennensis Lam.) no estado de Pernambuco (Brasil). Fitopatologia Brasileira 1:67-78. 1976.

SANTOS, E.S. Cultura do inhame (Dioscorea sp.). EMEPA, João Pessoa, PB. 8p. 2002.

SOMMER, N.F., BUCHANAN, J.R. \& FORTLAGE, R.J. Production of patulin by Penicillium expansum. Applied of Environmental Microbiology 4:589-593. 1974. 